
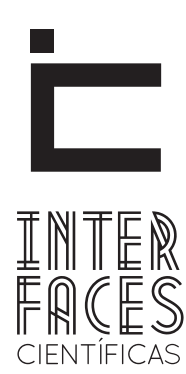

DIREITO

ISSN IMPRESSO 2316-3321

E - ISSN 2316-381X

DOI - 10.17564/2316-381X.2017v5n3p51-60

\title{
OS DIREITOS HUMANOS FUNDAMENTAIS NO BRASIL: UMA ANÁLISE SOBRE SUA EVOLUÇÃO E APLICAÇÃO
}

\section{THE FUNDAMENTAL HUMAN RIGHTS IN BRAZIL: AN ANALYSIS OF ITS EVOLUTION AND APPLICATION \\ DERECHOS HUMANOS FUNDAMENTALES EN BRASIL: UN ANÁLISIS DE SU EVOLUCIÓN Y APLICACIÓN}

\section{RESUMO}

Os Direitos Humanos Fundamentais compõem dentro da Constituição Federal Brasileira de 1988, comumente conhecida como Constituição Cidadã, um dos principais direitos a serem observados e efetivados pelo Estado brasileiro, sendo inserida logo no início do texto constitucional, diferentemente das demais constituições do país. Nesse sentido, o presente artigo procura demonstrar que tais direitos não foram meramente inseridos nela, mas são frutos de conquistas sociais históricas e de um processo evolutivo em que há uma compreensão sistemática do que sejam direitos humanos. 0 estudo também faz uma análise sobre a efetividade dos direitos da pessoa humana não apenas na seara do campo jurídico, mas também no campo fático, com a real aplicabilidade de tais direito na sociedade brasileira, pois essa é uma das maiores dificuldades hodiernas. Para tanto, utilizou-se de pesquisa metodologia qualitativa, calcada em método exploratório e descritivo, com base em doutrinas nacionais e internacionais, bem como sites.

\section{PALAVRAS-CHAVE}

Direitos Humanos Fundamentais. Direitos Sociais. Processo Evolutivo. Efetividade. 


\section{ABSTRACT}

Fundamental Human Rights comprise, within the Brazilian Federal Constitution of 1988, commonly known as the Citizen Constitution, one of the main rights to be observed and enforced by the Brazilian State, being inserted right at the beginning of the Constitutional text, unlike the other constitutions of the Country. In this sense, such paper tries to demonstrate that these rights were not merely inserted into it, but they are a result of historical social achievements and also an evolutionary process of a systematic understanding regarding what human rights are. The study also analyzes the effectiveness of human rights not only in the field of law but also in the factual field, with the real applicability of such rights in Brazilian society, as this is one of the greatest difficulties today. For that, we used a qualitative research methodology, based on exploratory and descriptive method, based on national and international doctrines as well as sites.

\section{KEYWORDS}

Fundamental Human Rights. Social Rights. Evolutionary Process. Effectiveness.

\section{RESUMEN}

Derechos humanos fundamentales constituyen en la Constitución Federal de Brasil de 1988, comúnmente conocida como la Constitución Ciudadana, uno de los principales derechos que deban ser observados y efectuado por el Estado brasileño, y se introduce al comienzo del texto constitucional, a diferencia de las otras constituciones del país. En este sentido, este artículo muestra que tales derechos no se limita a insertarse en ella, sino que son el resultado de los logros históricos y sociales de un proceso evolutivo donde hay una comprensión sistemática de lo que son los derechos humanos. El estudio también hace un análisis de la efectividad de los derechos de la persona humana no sólo la cosecha del ámbito jurídico, sino también en el campo de hechos con la aplicabilidad real de tales derechos en la sociedad brasileña, ya que este es uno de los mayores problemas de hoy. Por lo tanto, se utilizó la metodología de investigación cualitativa, basada en el método exploratorio y descriptivo, basado en las doctrinas y los sitios nacionales e internacionales.

\section{PALABRAS-LLAVE}

Derechos Humanos Fundamentales. Derechos Sociales. Proceso Evolutivo. Efectividad. 


\section{INTRODUÇ̃̃̃o}

Os direitos humanos fundamentais com a roupagem que conhecemos hoje tem sua gênese jurídica com as Revoluções dos séculos XVIII e XIX na Europa, momento a partir do qual documentos de proteção à pessoa humana de âmbito interno passam a ser elaborados, a exemplo da Constituição Francesa e da Constituição dos Estados Unidos da América.

Esses dois documentos têm em comum o fato de terem um viés humanitário, fator que também influenciou na criação de Constituições de outros Estados soberanos ao longo dos dois últimos séculos, em razão da ideia de que qualquer Constituição estatal, para ser reconhecida como tal, deveria tratar da proteção do ser humano.

Apesar de seu reconhecimento ser mais recente, se comparado com a existência dos direitos do homem, composto por direitos inatos ao ser humano e baseado no direito natural, os direitos humanos ou direitos humanos fundamentais ainda são pouco observados dentro do Estado brasileiro, tanto pelo próprio Poder Público como pela população que pouco conhecimento tem sobre o que de fato compõe esse ramo jurídico e o rol de direitos e deveres que o abarca.

Mas além da análise sobre a evolução dos direitos humanos fundamentais desde os seus primórdios, passando pela Revolução Francesa até chegar ao Brasil do século XXI, também se tem de averiguar como a aplicação/efetividade desse ramo do direito se dá em solo nacional, sobretudo no que tange aos direitos sociais, pois esses ainda são tratados por parcela da doutrina como não fundamentais.

Desse modo, visa-se estimular o debate a importância da efetividade fática dos direitos fundamentais tanto individuais como coletivos, bem como as possíveis alterações diante da postura do governo e da sociedade civil quanto a esses direitos inerentes à pessoa humana.

Para o desenvolvimento deste trabalho utilizou-se de pesquisa descritiva, qualitativa e exploratória, com uma análise interpretativa do tema baseado no levan- tamento bibliográfico por meio de doutrinas nacionais e internacionais, assim como de dados colhidos na internet.

\section{PROCESSO EVOLUTIVO DOS DIREITOS HUMANOS FUNDAMENTAIS}

A origem mais remota dos Direitos Humanos Fundamentais está relacionada à noção de direitos naturais (ius naturale, no latim) ou jusnaturalismo, que provêm primeiramente da Idade Antiga e passa pelas demais eras históricas até chegar aos nossos dias.

A teoria do jusnaturalismo tem como projeto avaliar as opções humanas com o propósito de agir bem e de modo razoável, o que, por sua vez, é alcançado por meio da fundamentação de determinados princípios do direito natural que são considerados bens humanos evidentes em si mesmos (FINNIS, 2007, p. 12).

Como influências mais importantes para os Direitos Humanos Fundamentais, tem-se o Código de Hammurabi, considerado o primeiro texto normativo codificado da história universal a consagrar uma série de direitos comuns, como a propriedade, a vida, a honra, a dignidade, a família; bem como a prever a supremacia das leis em face dos governantes (MORAES, 2000, p. 25).

Quanto à filosofia da Grécia Antiga, essa também possui importante influência para se chegar ao conceito de direitos humanos fundamentais, uma vez que corroborou no sentido de colocar a pessoa humana como centro da questão filosófica. Ou seja, passouse de uma explicação mitológica da realidade para uma explicação antropocentrista, possibilitando-se, então, refletir sobre a vida humana (MARTINS, 2003, p. 21). Neste mesmo sentido, houve milênios depois contribuição da reforma protestante que contestou a uniformidade da Igreja Católica, dando importância à interpretação pessoal das escrituras sagradas (LALAGUNA, 1993, p. 15). 
Já a Torah, (ou Pentateuco ou Lei de Moisés), que ainda hoje constitui texto central do judaísmo, escrita por volta do século XII a.C., traz um conjunto de regras religiosas, morais e sociais impostas obrigatoriamente ao povo de Israel (ARRUDA, 1995, p. 30), inclusive a igualdade entre os homens (CANTU, 2003, p. 259)

A própria formação judaico-cristã, sobretudo dos povos do ocidente, parece ter corroborado o entendimento de que há direitos que são inerentes à natureza humana, contribuindo a formação judaico-cristã na construção do que é o ser humano e, sobretudo, na construção de quais são os seus direitos.

Acerca de tal contribuição, Pinsky (2003, p. 15) afirma que, ao longo da história formou-se um monoteísmo ético. Trata-se de uma concepção revolucionária para a época do que é ser deus (ou, talvez, do que é ser humano, pois a partir do momento em que se tem um deus ético, desenha-se um ser humano ético). Desse modo, a tutela dos bens humanos, objeto do direito natural, seria, portanto, a tutela daquilo que é inerente ao ser humano e constitui elemento essencial para sua construção enquanto tal, o que, claramente, confunde-se com o conceito de tutela dos direitos humanos.

Nessa mesma senda, Dalmo de Abreu Dallari (2000, p. 54) afirma que:

\begin{abstract}
No final da Idade Média, no século XIII, aparece a grande figura de Santo Tomás de Aquino, que, tomando a vontade de Deus como fundamento dos direitos humanos, condenou as violências e discriminações, dizendo que o ser humano tem direitos naturais que devem ser sempre respeitados, chegando a afirmar o direito de rebelião dos que forem submetidos a condições indignas.
\end{abstract}

A partir da segunda metade da Idade Média, começa-se a difundir documentos escritos, reconhecendo-se direitos a determinadas classes sociais e comunidades, mas não ainda a todas as pessoas, não existindo qualquer proposta de universalização (FERREIRA FILHO, 1998, p. 11), a exemplo da Magna Carta Libertatum de 1215, outorgada pelo rei inglês João Sem-Terra, que reconheceu vários direitos, tais como a liberdade eclesial, a não existência de impostos sem anuências dos contribuintes, a propriedade privada, a liberdade de ir e vir e a desvinculação da lei e da jurisdição da pessoa do monarca, mas não a todos os ingleses (COMPARATO, 2003, p. 79-80).

Tem-se que o fundamento ético avança na história e, ao longo dela, reconhece-se a relevância das revoluções inglesa, americana e francesa para o reconhecimento de direitos inerentes a pessoa humana e suas respectivas influências nas constituições do século XIX (RUBIO, 1998, p. 82).

No que se refere à Revolução Inglesa (1640 a 1688), essa é considerada a primeira revolução burguesa da história, representando a transição de um capitalismo comercial para um capitalismo industrial; a formação de um novo modelo econômico e também a formação de uma monarquia constitucional. Ou seja, um Estado absolutista, gerido por monarcas, mas com dominação econômica de classes burguesas, no qual se desenha um estado pautado no modelo individualista hobbesiano(SMANIO, 2009, p. 15).

Vale dizer que de um ponto de vista social hobbesiano, o ser humano se encontrando num mundo hostil buscou reagir a estas hostilidades, inventando técnicas de sobrevivência por meio de sistemas de regras (BOBBIO, 1992, p. 28), inaugurando-se a partir de então o liberalismo com a proteção dos direitos civis por meio de uma carta de direitos - a Bill of Rights.

A Revolução Americana, por sua vez, efetivada com a declaração de independência dos Estados Unidos da América de 1776 e com a Constituição de 1787, trata-se de outra revolução burguesa muito importante, uma vez que significa aprofundar-se no indivíduo e garantir sua proteção econômica e privada (SMANIO, 2009, p. 15).

Ainda sobre a Revolução Americana, Norberto Bobbio entende que, além da proteção econômica e privada do indivíduo, ela teve como seu fundamento: “[...] o direito natural; idêntico era o desfecho, o governo fundado no contrato social, a república como governo que rechaça para sempre a lei da hereditariedade, a democracia como governo de todos" (Grifo nosso).

Mas é com a Revolução Francesa, a terceira revolução burguesa, que é fundada a ideia de direitos naturais (liberdade, igualdade e fraternidade) e, por meio da Declaração de Direitos do Homem e do Cidadão de 26 de agosto de 1789, dá-se uma dimensão jurídica e política à cidadania liberal (SMANIO, 2009, p. 15). 
Posteriormente, outras constituições ${ }^{1}$ inspiraramse nos modelos americano e francês, sobretudo, no que diz respeito à garantia e defesa destes direitos naturais ao ser humano. Desta forma, o desenvolvimento dos direitos humanos seguiu seu curso afirmandose durante o constitucionalismo liberal do século XIX, adquirindo, a partir do século XX, característica de universalidade (DA SILVA, 2016, p. 12).

Percebe-se, portanto, que o século XVIII representou a conquista dos direitos civis (vida, liberdade, propriedade e igualdade perante a lei), didaticamente denominado de direitos de $1^{\mathrm{a}}$ geração ou dimensão, juntamente com os direitos políticos. O século XIX, por sua vez, representou a conquista dos direitos políticos, uma vez que a principal discussão versava sobre a participação popular no governo. Por fim, o século XX representou as conquistas no âmbito dos direitos sociais (SMANIO, 2009, p.16), que ao lado dos direitos econômicos e culturais são denominados de direitos de $2^{\mathrm{a}}$ geração ou dimensão.

Foi desse modo que o início do século XX trouxe diplomas fortemente marcados pelas preocupações sociais. Neste sentido, Vicente Bagnoli (2005, p. 33), aponta para três documentos pautados nestas preocupações: a encíclica Rerum Novarum de $1891^{2}$ Constituição do México de 1917, a Constituição Alemã ou de Weimar de 1919, essa última influenciando na criação da Constituição da República dos Estados Unidos do Brasil de 1934.

A Constituição Mexicana é considerada marco normativo em matéria de direitos humanos fundamentais porque garantiu direitos individuais com fortes tendências sociais, sobretudo no campo trabalhista (artigo $5^{\circ}$ ) e no que diz respeito à efetivação da

\footnotetext{
1 Nesse sentido, vale citar o exemplo da Constituição Espanhola, de 19 de março de 1812 (Constitución de Cádiz), popularmente conhecida como "La Pepa”, que previa o princípio da legalidade, restrições aos poderes do rei, o princípio do juiz natural, a proibição de tributos arbitrários, o direito de propriedade, a desapropriação mediante justa indenização e a liberdade; bem como a constituição portuguesa, de 23 de setembro de 1822, que, por sua vez, consagrou: direitos: à liberdade, à segurança, à propriedade, à inviolabilidade do domicilio, à igualdade perante a lei, à liberdade de expressão, liberdade de imprensa, ao sigilo de correspondência, à educação e à assistência, a proibição da prisão sem culpa formada, a humanização do direito penal com a proibição de todas as penas cruéis (tortura) e/ou infamantes e a humanização do direito penitenciário (DA SILVA, 2016).

2 Publicada pelo Papa Leão XIII, a encíclica trata da condição dos operários e propõe auxílio a estes homens.
}

educação (artigo $3^{\circ}$ ) (DA SILVA, 2016, p. 14). Já sobre a Constituição de Weimar³ ${ }^{3}$ Gilberto Bercovici (2005, p.18) entende que ela divide-se em três níveis:

\begin{abstract}
O primeiro nível seria o dos direitos fundamentais, sociais e econômicos, como o direito ao trabalho (art. 163), a proteção ao trabalho (art. 157), o direito à assistência social (art. 161), e o direito de sindicalização (art. 159). Outro nível social seria o do controle da ordem econômica capitalista por meio da função social da propriedade (art. 153) e da possibilidade de socialização (art. 156). Finalmente, o terceiro nível seria o mecanismo de colaboração entre trabalhadores e empregados por meio de conselhos (art. 165). Com esta organização, a ordem econômica de Weimar tinha o claro propósito de buscar a transformação social, dando um papel central aos sindicatos para a execução desta tarefa.
\end{abstract}

A Segunda Guerra Mundial, considerada a guerra mais abrangente e mais letal da história humana, marcada por um número significante de ataques contra civis, incluindo o Holocausto e o uso de armas nucleares, demonstrou que os direitos dos indivíduos enquanto seres humanos deveriam ser protegidos em escala global, por meio do direito internacional (DA SILVA, 2016, p. 12).

Com o fim da II Guerra mundial e a derrota dos Estados totalitários nazifacistas, 51 (cinquenta e um) países reuniram-se em São Francisco, nos Estados Unidos da América, e firmaram a Carta das Nações Unidas em 26 de junho de $1945^{4}$, espelhando a preocupação com a internacionalização de direitos humanos desde seu preâmbulo.

Três anos mais tarde a Assembleia Geral das Nações Unidas (AGNU), adotou a Declaração Universal

\footnotetext{
3 Sobre as origens históricas da constituição de Weimar, Bagnoli (2005, p. 33) aponta que: "[...] antes mesmo da celebração do armistício da Primeira Guerra de 11 de novembro de 1918, a Alemanha foi palco de diversas disputas internas que culminaram na República de Weimar. Na noite de 7 de novembro, proclama-se na Baviera uma República Democrática e Socialista por meio dos partidos de esquerda mais radicais. Aos 9 de novembro, o partido socialista alemão proclama a República na chancelaria de Berlim. No final de 1918, já com uma nova lei eleitoral, realizam-se as eleições para formar 0 congresso dos representantes das províncias imperiais, que, eleito, vota em janeiro de 1919 pela convocação da Assembleia Nacional Constituinte”.

4 A Liga das Nações foi substituída pela Organização das Nações Unidas neste contexto pós segunda Guerra. Vale lembrar que, embora não tivesse a mesma pretensão de internacionalização de direitos inerentes ao ser humano, já apresentava preocupações relativas a causas como: a escravidão, mulheres envolvidas em prostituição, direitos dos trabalhadores e a proteção de algumas minorias (CLAPHAM, 2007, p. 28).
} 
de Direitos Humanos de $1948^{5}$, sobre a qual Norberto Bobbio (1992, p. 18) afirma:

\begin{abstract}
Com a Declaração de 1948, tem inicio uma terceira e última fase, na qual a afirmação dos direitos é, ao mesmo tempo, universal e positiva: universal no sentido de que os destinatários dos princípios nela contidos não são mais apenas os cidadãos deste ou daquele Estado, mas todos os homens; positiva no sentido de que põe em movimento um processo em cujo final os direitos do homem deverão ser não mais apenas proclamados ou apenas idealmente reconhecidos, porém efetivamente protegidos até mesmo contra o próprio Estado que os tenha violado. (Grifo nosso).
\end{abstract}

Percebe-se, portanto, uma forte revolução no que diz respeito à amparo dos direitos de proteção à pessoa humana ganham universalidade, o que significa dizer que qualquer ser humano deve possuir sua natureza humana preservada e protegida, inclusive, abrigada em relação ao seu próprio Estado da qual é nacional.

Com isso verifica-se que os direitos inerentes à pessoa humana evoluíram de uma conceituação tradicional de direito natural desenvolvida por filósofos para direitos positivos particulares mediante os direitos humanos fundamentais até chegar a sua plena realização como direitos positivos universais de âmbito internacional global e regional, tais como os Sistemas Americano ${ }^{6}$, Africano $^{7}$ e Europeu ${ }^{8}$ (CLAPHAM, 2007, p. 52).

\footnotetext{
5 Sobre esta mudança de nomenclatura, embora os temas sejam mais discutidos a frente, é importante salientar que tais mudanças contemplam uma evolução, sobretudo, na temática dos gêneros, visto que se faz necessário proteger os direitos de qualquer ser humano (independentemente de seus mais diversos gêneros) e, também, independentemente de serem considerados cidadãos ou não, uma vez que o conceito de cidadão e nacional confunde-se e, dessa forma, a referida terminologia pode tornar-se excludente. 6 Sob a gestão da Organização dos Estados Americanos (OEA), o sistema interamericano de direitos humanos tem ganhado forças nas Américas, sobretudo, posteriormente à edição do Pacto de São José da Costa Rica, o qual tem colocado em discussão diversos dispositivos no âmbito legal e constitucional nos Estados americanos. Um exemplo é a Opinião Consultiva n. 5/85, na qual a Corte Interamericana de Direitos Humanos (corte internacional que integra o sistema da OEA) manifestou-se contraria à obrigatoriedade do diploma e da inscrição em ordem profissional para o exercício da profissão de jornalista, o que, por sua vez, influencio decisão recente do Supremo Tribunal Federal brasileiro sobre o tema.

70 sistema regional africano de proteção dos direitos humanos desenvolveu-se na Organização de Unidade Africana (OUA), atual União Africana. O seu principal instrumento de direitos humanos é a Carta Africana dos Direitos do Homem e dos Povos de1981 (DIREITOS HUMANOS).

8 Importante salientar que a Corte Europeia de Direitos Humanos, também integrada dentro do Sistema Europeu de Direitos Humanos, tem julgado mais de mil casos ao ano (CLAPHAM, 2007, p. 52).
}

No Brasil, por sua vez, os direitos civis e políticos têm início com a Constituição da República dos Estados Unidos do Brasil de 1891, porém com direitos endereçados somente a uma parcela da sociedade da época, enquanto os direitos sociais têm lugar pela primeira vez com a Constituição da República dos Estados Unidos do Brasil de 1934, que sofreu influência da Constituição de Weimar de 1919.

Já a atual Constituição da República Federativa do Brasil de 1988 é reconhecida como o marco do processo de democratização do país, porque consolida, em termos normativos, a interrupção do regime militar instalado em 1964. A demarcação jurídica da transição do regime militar e seu autoritarismo para um regime democrático é verificada pela ampliação dos direitos e garantias fundamentais (DA SILVA, 2016, p. 12).

Sobre os direitos fundamentais elencados na Constituição de 1988, Flávia Piovesan (1996, p. 72) aponta que os valores constitucionais compõem: um contexto axiológico básico para a interpretação de todo o ordenamento jurídico; um postulado-guia para orientar a hermenêutica teleológica e evolutiva da Constituição; e um critério para medir a legitimidade das diversas manifestações do sistema de legalidade. Dessa forma, percebe-se, portanto, uma sistematização para que se seja possível articular tais direitos e os garantir.

A efetivação da democracia por meio do texto constitucional brasileiro, além do rol de direitos fundamentais nela elencados, bem como as suas garantias e a sua sistemática articulada colocou o Brasil de um contexto de ditadura em um contexto, ao menos, no âmbito textual, em mesmo patamar que a maioria de centenárias democracias desenvolvidas no que se refere à promoção e efetivação dos direitos humanos.

\section{APLICAÇ̃̃O DOS DIREITOS HUMANOS FUNDAMENTAIS E SOCIAIS NO BRASIL}

De acordo com Ingo Sarlet (2003, p. 221) a aplicação dos direitos fundamentais relaciona-se a dois pontos: a eficácia social e a eficácia jurídica. Contudo, como bem elucida José Afonso da Silva, apesar do 
elo estreito entre os dois tipos de eficácia, ambas se diferem em função de seus efeitos, pois enquanto 0 segundo é a aplicação dos efeitos jurídicos, a primeira é a aplicação fática da norma (SILVA, 1998, p. 65-66)

No mesmo sentido, Uadi Lammêgo Bulos (2015, p. 477-478), traz que:

Eficácia normativa ou técnico-jurídica é a simples possibilidade de aplicação da norma constitucional. Não se busca aqui o sucesso da Carta Magna, mas a sua aptidão técnica para produzir efeitos jurídicos [...] Eficácia social ou sociológica é a incidência concreta e regular das normas constitucionais sobre os acontecimentos da vida. É o mesmo que efetividade [...]

Apesar do rol extenso de direitos humanos fundamentais contidos da Constituição da República Federativa do Brasil de 1988 (CF/88) em seu artigo $5^{\circ} \mathrm{e}$ sociais no artigo $6^{\circ}$ (de modo genérico), na prática se percebe uma inobservância de parcela dos mesmos, isto tanto no que tange ao próprio Poder Público, quanto à sociedade como um todo (particulares).

Exemplos dessa realidade são a educação pública e a saúde básica deteriorada no país, a segurança pública descompassada com a realidade social, o direito à vida sendo mitigado com casos de linchamentos diante de possíveis delitos, casos de cárceres privados de ex-namorados ou ex-maridos em face de suas companheiras, colocando em xeque a liberdade de locomoção, dentre outras situações de nítida violação aos direitos humanos fundamentais.

Ademais, parcela considerável da população brasileira não sabe o que são os direitos humanos fundamentais e nem mesmo o que visa proteger, reduzindo de modo equivocado e falacioso à proteção de "bandidos", quando na verdade abrange um rol de direitos inerentes a toda pessoa humana, esteja o indivíduo encarcerado ou não.

No caso dos direitos civis e políticos, considerados em regra como direitos de defesa (e.g. liberdade de locomoção, liberdade religiosa), a aplicação costuma ser mais simples, pois nem sempre dependem de uma prestação estatal para que possam ser usufruídos ${ }^{9}$, sendo, portanto, tidos como de aplicação imediata conforme prevê o artigo $5^{\circ}, \S 1^{\circ} \mathrm{da} \mathrm{CF} / 88$.

90 exercício dos direitos políticos, mediante o voto, é um exemplo de exceção a não exigência prestacional do Estado (recurso financeiro).
No que se refere aos direitos sociais (coletivos), há uma maior dificuldade em sua aplicação em função de dois fatores. 0 primeiro deles é a própria resistência de parte doutrinária em considerar que direitos como educação, assistência social, moradia, dentre outros elencados no artigo $6^{\circ}$ de nossa Lei Maior sejam de fato autênticos direitos fundamentais, em que ainda tem-se parcela da doutrina que defende que os direitos sociais são meramente programáticos.

Porém, conforme pontua Ingo Sarlet (2017, p. 6)

\begin{abstract}
[...] o Poder Constituinte de 1988 acabou por reconhecer, sob o rótulo de direitos sociais, um conjunto heterogêneo e abrangente de direitos (fundamentais), o que, sem que se deixe de admitir a existência de diversos problemas ligados a uma precária técnica legislativa e sofrível sistematização (que, de resto, não constituem uma particularidade do texto constitucional, considerando o universo legislativo brasileiro) acaba por gerar consequências relevantes para a compreensão do que são, afinal de contas, os direitos sociais como direitos fundamentais. (Grifo nosso).
\end{abstract}

O segundo fator se refere "[...] a problemática da eficácia e efetividade dos direitos fundamentais sociais [...]" (SARLET, 2017, p. 4), pois esses dependem em maior escala de uma prestação do Estado (a exceção de alguns que são direitos de defesa), situação que demanda um agir do Poder Público com vistas a propiciar "o bem-estar do povo, à sua segurança económica e social” (CANOTILHO, 2003, p. 475).

É justamente nessa seara que surge alguns entraves, pois ao se tratar os direitos sociais como fundamentais, retira-se a ideia de que são meras intenções políticas e transforma-se em direitos que devem ter efetividade não apenas jurídica, mas também fática e, portanto, devem ser postos em prática mediante políticas públicas estatais com observância ao que determina o princípio da reserva do possível.

Vale frisar que a reserva do possível tem um papel secundário, uma vez que o Poder Público deve comprovar não possuir recursos para a efetivação de direitos coletivos constitucionais e essenciais à sociedade. Caso contrário não poderá se eximir de tal obrigação, podendo inclusive ser alvo de judicializações para que 
tais direitos se concretizem, não sendo incomuns casos na justiça brasileira, envolvendo solicitação de vagas em creches e escolas ou, de remédios e cirurgias para tratamentos de saúde.

\section{CONSIDERAÇÕES FINAIS}

Percebe-se que a valorização do ser humano e o reconhecimento que sua existência digna necessita de que direitos mínimos sejam reconhecidos faz parte da história da vida humana, tanto no que se refere a direitos individuais como coletivos.

Verifica-se também que a evolução deste reconhecimento dá-se até alcançar-se uma sistemática internacional de proteção de direitos humanos e uma proteção constitucional destes direitos. Todavia, conforme também apontado, apesar da evolução dos direitos inerentes à pessoa ao longo da história do Brasil e do mundo, tais direitos ainda não garantem, em regra, igualdade a todos, sobretudo no que tange aos direitos sociais.

Essa celeuma se dá em virtude de que ainda existe a visão de que somente os direitos fundamentais individuais são passíveis de terem eficácia jurídica e social, deixando-se em segundo plano os direitos sociais, muitos dos quais vitais à proteção da dignidade humana.

Sendo assim, o debate sobre quais serão os próximos caminhos que os direitos humanos fundamentais, em sentido lato, precisam traçar para evoluir ainda mais e tornar tais direitos realmente efetivos ainda permanecem.

\section{REFERÊNCIAS}

\section{ARRUDA, José Jobson de A. História antiga e} medieval. 13.ed. São Paulo: Ática, 1995.

BAGNOLI, Vicente. Direito e poder econômico. São Paulo: Atlas, 2005.

BERCOVICI, Gilberto. Constituição econômica

e desenvolvimento: uma leitura a partir da

Constituição de 1988. São Paulo: Malheiros, 2005.
$\mathrm{BOBBIO}$, Norberto. A era dos direitos. Rio de janeiro: Campus, 1992.

BULOS. Uadi Lammêgo Bulos. Curso de direito constitucional. São Paulo: Saraiva, 2015.

\section{CANOTILHO, Joaquim José Gomes. Direito} constitucional e teoria da constituição. Coimbra: Almedina, 2003.

CANTU, Césare. História universal. V.1. São Paulo: Américas, 2003.

CLAPHAM, Andrew. Human rights: a very short introduction. New York: Oxford, 2007.

COMPARATO, Fábio Konder. A afirmação histórica dos direitos humanos. 3.ed. São Paulo: Saraiva, 2003.

DALLARI, Dalmo de Abreu. A Luta pelos Direitos Humanos. In: LOURENÇO, Maria Cecília França. Direitos humanos em dissertações e teses da USP: 1934-1999. São Paulo: Universidade de São, 1999.

\section{DA SILVA, Luiza Gomes. A evolução dos}

direitos humanos. Disponível em: <http://www. conteudojuridico.com.br/artigo,a-evolucao-dosdireitoshumanos,42785.html\#_ftn 187>. Acesso em: 29 dez. 2016.

FERREIRA FILHO, Manoel Gonçalves. Aspectos do direito constitucional contemporâneo. São Paulo: Saraiva, 2003.

FINNIS, John. Lei natural e direitos naturais (Tradução de Leila Mendes). São Leopoldo: Unisinos, 2007.

LALAGUNA, Paloma Durán. Manual de derechos humanos. Granada: Comares, 1993.

MARTINS, Flademir Jerônimo Belinati. Dignidade da pessoa humana: princípio constitucional fundamental. Curitiba: Juruá, 2003. 
MORAES, Alexandre de. Direitos humanos

fundamentais: teoria geral (comentários aos artigos $1^{\circ}$ a $5^{\circ}$ da Constituição da República Federativa do Brasil - doutrina e jurisprudência. Coleção Temas Jurídicos, v.3, São Paulo: Atlas, 2000.

PINSKY, Jaime. Os Profetas Sociais e o Deus da Cidadania. In: PINSKY, Jaime, PINSKY, Carla Bassanezi (Org.). História da cidadania. São Paulo: Contexto, 2003.

\section{PIOVESAN, Flávia. Direitos humanos e o direito constitucional internacional. São Paulo: Max} Limonad, 1996.

\section{RUBIO, Valle Labrada. Introduccion a la teoria} de los derechos humanos: Fundamento. Historia. Declaración Universal de 10 de diciembre de 1948. Madrid: Civitas, 1998.
SARLET, Ingo Wolfgang. A eficácia dos direitos fundamentais. Porto Alegre: Livraria do Advogado, 2003.

SARLET, Ingo Wolfgang. Os direitos sociais como direitos fundamentais: contributo para um balanço aos vinte anos da Constituição Federal de 1988. Disponível em: <www.stf.jus.br/arquivo/.../artigo_ Ingo_DF_sociais_PETROPOLIS_final_01_09_08.p>. Acesso em: 18 jan. 2017.

SILVA, José Afonso da. Aplicabilidade das normas constitucionais. São Paulo: Malheiros, 1998.

SMANIO, Gianpaolo Poggio. Dimensões da cidadania. In: Novos Direitos e Proteção da Cidadania - Revista jurídica da escola superior do Ministério Público. Ano 2 - janeiro/junho 2009.
1 Doutoranda em Direito Político e Econômico pela Universidade Presbiteriana Mackenzie; Bolsista Capes no Programa de Doutorado Sanduíche na Universidad Complutense de Madrid; Mestre em Ciências-Jurídico Internacionais pela Universidade de Lisboa, Portugal com revalidação pela Universidade Estadual do Rio de Janeiro - UERJ; Especialista em Relações Internacionais pela Pontifícia Universidade Católica de Minas Gerais - PUC/MG e em Direito Público pela Universidade Católica Dom Bosco - UCDB; Graduada em Ciências Jurídicas pela Universidade Católica Dom Bosco; Professora Assistente da Universidade Federal do Mato Grosso do Sul - UFMS no campus de Três Lagoas; Possui experiência na área de direito público, com ênfase em direitos humanos, direito constitucional e direito internacional (docência e pesquisa); Atua com temas relacionados aos grupos vulneráveis, como crianças, idosos, mulheres e indígenas, bem como a questão da migração e do refúgio, ministrando aulas em cursos de graduação nas cidades de Campo Grande (Uniderp, FCG, Facsul e UFMS), Rio Verde de Mato Grosso (Uniderp) e Três Lagoas (UFMS) e, pós-graduação lato sensu em Campo Grande (Unilins/ Acadepol). E-mail: professoraisabellesantos@gmail.com

2 Tradutor; Doutorando em Direito Político e Econômico pela Universidade Presbiteriana Mackenzie (com bolsa integral Capes/Taxa; Mestre em Direito Político e Econômico pela Universidade Presbiteriana Mackenzie (com bolsa integral do MackPesquisa); Especialista em Direito Público pela Universidade Cândido Mendes e em Direito e Processo Civil pela Universidade Cândido Mendes; Graduado em Direito pela Universidade Presbiteriana Mackenzie; Professor convidado do curso de direito societário e direito civil do programa de pós graduação da Universidade Presbiteriana Mackenzie e do CPP Concursos; Tem experiência profissional em Direito Civil, Direito Empresarial, Direito Bancário, Direito Econômico, Direitos Humanos, Direito Constitucional e Direito Tributário; Foi advogado atuante na áreas de Direito Econômico e Regulação Financeira do Banco Bradesco de Investimentos, da Bradesco Securites e do Banco Safra. E-mail: bertoncello.fernando@gmail.com 
